\title{
THE TRAINING OF \\ SECONDARY SCHOOL TEACHERS OF MATHEMATICS \\ IN THE FEDERAL REPUBLIC OF GERMANY
}

\section{G. Pickert}

Mathematisches Institut, Justus Liebig-Universität, Giessen

The school system in the Federal Republic of Germany consists mainly of three different types of schools:

1) Volksschule (elementary school) with 8 grades (planned to be extended to 9 grades), entrance age 6-7 years. At the end of the 4th grade, about 30-40 percent of the pupils leave this school, entering one of the two types of secondary schools. (Usually an entrance examination is required.)
2) Mittelschule with 6 grades.
3) Gymnasium with 9 grades. The Gymnasium concludes with a somewhat severe examination, the "Abitur" or "Maturum" (matriculation). Aside from a few exceptional possibilities, the Abitur is a necessary and sufficient prerequisite for entering a University or any other educational institution of university rank. In the following, only the Gymnasium is referred to as High School, and a high school teacher is one teaching in a Gymnasium. As we are concerned with the mathematics teacher here, it should be mentioned that in the last two years of the high school, elementary calculus, as well as elementary analytical geometry, is taught.

To become a high school teacher one has to study at least 4 years at a university or at a "Technische Hochschule" (institutions of university rank, primarily for the training of engineers). On entering a university the student has to register in a faculty. For the future mathematics teacher this will be the faculty of science in most universities ("Naturwissenschaftliche Fakultät" or "Mathematisch-Naturwissenschaftliche Fakultät"). As the student is not asked to state the goal of his studies, the lectures on mathematics are attended by those who look forward to careers as mathematics teachers at the high school or University level as well as by students who want to enter careers in industry as mathematicians or physicists. At the beginning of the university studies the student is allowed 
to specialize. This means that the prospective mathematics teacher may limit his studies to mathematics and one other discipline, usually physics. However, he ${ }^{1)}$ must also pass separace examinations in philosophy and pedagogy (sometimes also in political science) after at least 3 years of studies. This "Philosophicum" is not as important as the final examination in mathematics and physics, and the preparation for it should consume only a relatively small part of the student's time. In the following, only the mathematical studies are described, but it is understood that the student is supposed to study his second discipline, say physics, to a somewhat similar extent.

In the first year the student should attend the lectures on advanced calculus (called either "Analysis" or "Differential-und Integralrechnung") and analytical geometry. The latter serves as an introduction to $\mathrm{n}$-dimensional geometry, linear algebra and projective geometry. The lectures are complemented by "Übungen", which may be described as mathematical laboratory work where problems are done either as homework or in small groups of 20-30 students working under the guidance of an "Assistent" (perhaps comparable to a graduate assistant). In contrast, the lectures themselves are not sectioned and are attended by one hundred or more students (in some universities, by several hundred). Some lectures at a more advanced level than those just mentioned also have "Übungen". At the end of each term the students who have successfully completed the work in the "Übungen" get certificates (Übungsscheine). Sometimes the se "Übungsscheine" are based on a written examination. In general, the student is not forced to attend the lectures in any set order, but naturally the mathematics department gives advice.

The mathematical knowledge the student should acquire during his studies, if he wants to become a high school teacher, may roughly be described as follows ${ }^{2}$ ): a deeper understanding

1) This should not imply that all future high school teachers are necessarily men; but the percentage of women mathematics teachers is indeed small.

2)

Everyone of the 11 states of the Federal Republic has somewhat different regulations. 
of elementary mathematics and its scientific foundations; good knowledge of advanced calculus and analytical geometry (in the sense described above); a working knowledge of algebra (in the sense of "Modern Algebra"); the theory of functions of a complex variable; differential equations; differential geometry; the elements of general topology; the more important methods of descriptive geometry; "Praktische Mathematik" (numerical and graphical methods in analysis); a general view of the history of mathematics.

Thus the high school teacher should not restrict his studies only to those branches of mathematics which are taught in high school. He ought to have an idea of mathematics as a whole, so that he may be able to answer questions going beyond the high school level.

At some universities lectures are given, especially designed for the prospective high school teacher, on the scientific background and foundations of high school mathematics - somewhat in the tradition of Felix Klein's "Elementarmathematik von höheren Standpunkt aus" (Elementary Mathematics from an advanced viewpoint, $19083 \mathrm{rd}$ edition 1925, Translated by E. Hedrick and C. Noble, Dover). Here the topics taught in high school are embedded in, and connected with, general mathematical theories so that the student may see how the growing science of mathematics can influence the teaching of elementary mathematics. At some universities special courses are given by experienced high school teachers in which the students are introduced to the didactics of mathematics.

Besides the lectures and the "Übungen" connected with them, the student has to take part in three seminars. In each of the se he has to hold a lecture (usually 45 to 90 minutes long) based on mathematical literature assigned to him by the professor. The first seminar is usually attended after the end of the second year. In most cases sections from textbooks are assigned. In the two other seminars, research papers or sections from monographs will be chosen. Usually the student needs substantial help, either from the professor or his assistant, in preparing the lecture. Seminars are the decisive steps during the studies. Here the student must prove not only that he understands a mathematical problem but that he is also able to present it to a critical audience. 
The final examination, called "1. Staatsexamen" (or "Wissenschaftliches Staatsexamen") is taken after five or six years of studies (on the average). The student must present the required certificates for the "Übungen" and the three seminars. If, as will be supposed here, his main interest lies in the field of mathematics, he has to write a thesis on a mathematical subject assigned to him by one of his professors. This the sis may be thought of as equivalent to a Master's thesis in Canada. Then he has to pass written and oral examinations in mathematics and the other discipline (say physics). No the sis is required in his second subject.

Having passed this examination, the candidate goes to a high school as "Studienreferendar"to receive his practical pedagogical training. Under the tutelage of a senior teacher (one for each discipline i.e., mathematics and physics as here considered) specially appointed for this duty, the "Studienreferendar" learns to conduct a class. Beside this, he attends special seminars on pedagogy and didactics. After two years he takes the "2. Staatsexamen" (or "Pädagogisches Staatsexamen"). For this he must write a the sis on a question of mathematical didactics - in most cases connected with teaching experience he has gained in his years as "Studienreferendar". Nowadays, such a thesis very often describes an experiment with new mathematical concepts or methods formerly not used in the high school. Upon passing the "2. Staatsexamen" the "Studienreferendar" becomes a "Studienassesor" and, as such, teaches classes on his own. Usually after four more years of service, the "Studienassesor" is promoted to "Studienrat". His further career doesn't depend on in-service training and is therefore of no importance for this report.

Substantial in-service training for high school teachers does not exist in the Federal Republic of Germany. This is an essential drawback to the educational system which cannot be compensated for by the relatively long duration of studies. The danger arises that the high school teacher will not become aware of essential new developments in mathematics, and thus the gap between those mathematical topics taught in high school and the science of mathematics being taught and developed at the University may widen. This danger is seen by the high school teacher as well as by the University professor. At meetings of the teacher's organization "Deutscher Verein zur 
Förderung des mathematisch-naturwissenschaftlichen Unterrichts" (German Association for the advancement of the teaching of Mathematics and Natural Sciences) reports are given on mathematical concepts and methods which will be of importance for the teaching of mathematics in the high school. On their own initiative and with the financial help of the government, University professors give special courses and organise meetings for teachers in an attempt to keep them in contact with the development of mathematics. At some universities, professors especially interested in the training of high school teachers have created a so-called "Seminar fúr Didaktik der Mathematik". High school teachers from cities and towns near the University are invited to the sessions of such a seminar. Either a student or an invited guest (University professor or high school teacher) will speak about a mathematical concept or method which may be useful in high school teaching. If the speaker is a teacher, he may also report on his own classroom experience. If not, then the discussion with the teachers afterwards will give the necessary practical addition. Thus, these sessions on the one hand show the students the problems associated with their future professions, and on the other hand try to keep the high school teachers in contact with the University.

The first "Seminar für Didaktik der Mathematik" was founded by Professor Behnke in Münster. It is hoped that the number of such seminars will increase and that the new one $s$ will also prove to be centres of continuous voluntary in-service training of high school teachers. 
